\title{
The investigation of the relationship between smartphone addiction, and problem-solving skills and ways of coping with stress
}

\author{
Rana Alan $^{1}$, Halime Senay Guzel ${ }^{\circledR}$ \\ ${ }^{1}$ Abant Izzet Baysal University, General Psychology Master Student, Psychologist - Ankara \\ ${ }^{2}$ Ankara Yildirim Beyazit University, Faculty of Humanities and Social Sciences, Department of Psychology, Ankara - Turkey
}

\begin{abstract}
Objective: This study mainly aims to investigate the relationship between smartphone addiction in adults and their problem solving skills and the way they deal with stress. It is also intended to examine the sociodemographic variables associated with smartphone addiction.

Method: The sample of the study comprises 306 adults (183 female 123 male). Problem Solving Skills Inventory, Coping With Stress Inventory, Smartphone Addiction Scale and Demographic Information Form were used to collect data. The SPSS 25.0 package program was used to analyze the data and the significance level was accepted as $p<0.05$ in all statistical evaluations.

Results: In the study, participants without having self-confident style in coping with stress were hown to have a higher degree of smartphone addiction than those chosen the other coping sytles. Moreover, it was found that smartphone addiction scores are significantly higher in male participants than female, and in those in their early adulthoods than in their middle one, and that the level of smartphone addiction increases as the daily smartphone usage time increases.
\end{abstract}

Conclusion: According to the results of the study, it was found that the way of coping with stress was especially effective on smartphone addiction which is currently considered as a behavioral addiction.

Keywords: Coping with stress, problem-solving skill, smartphone addiction

\section{INTRODUCTION}

The features of smartphones can be listed as providing users with advanced connectivity preferences (such as GPS, WiFi, 3G, Bluetooth), recording audio and video, internal or addons- memory, and the ability to have mobile operating systems running many applications at the same time (1). Smartphones make life easier for individuals, as they enable both quick access to information and taking the Internet with them wherever they go. For this reason, it has become increasingly important in the lives of individuals (2). In addition to these positive features, the use of smartphones has started to cause problems in terms of "addiction" such that technological addictions are said to be based on human-machine interaction (3). Although smartphone addiction has not yet been considered as a diagnosis in diagnostic manuals such as the Diagnostic and

How to cite this article: Alan R, Guzel HS. The investigation of the relationship between smartphone addiction, and problem-solving skills and ways of coping with stress. Dusunen Adam The Journal of Psychiatry and Neurological Sciences 2020;33:244-253.

Correspondence: Halime Senay Guzel, Ankara Yildirim Beyazit University, Faculty of Humanities and Social Sciences, Department of Psychology, Ankara - Turkey

E-mail: senaysenyuva35@gmail.com

Received: January 02, 2020; Revised: March 27, 2020; Accepted: June 09, 2020 
Statistical Manual of Mental Disorders (DSM) and International Classification of Diseases (ICD), it has been revelaed that four important factors such as compulsive behavior, functional impairment, deprivation and tolerance, and discovery factor are symptoms of smartphone addiction (4). As a matter of fact, according to Lin et al. (4), smartphone addiction has many parallel aspects to substance addiction and addiction disorder in DSM-5, the diagnostic and classification system used today. Another study by Kwon et al. (5), stated that smartphone addiction negatively affects the lives of addicted individuals through tolerance, excessive desire, deterioration of social relations, and loss of control. Therefore, these researchers define smartphone addiction as a behavioral addiction $(4,5)$.

Scrutinizing the relevant literature, it has been seen that the relationship of many variables with smartphone addiction is investigated. In particular, many studies show the relationship between depression, anxiety, attachment problems, loneliness, and anger with smartphone usage (6-10). In addition to these variables researched in relation to smartphone addiction, it can be said that how an individual copes with stressful events is also quite important. The concept of coping with stress, first used by Folkman and Lazarus (11), is defined as the cognitive and behavioral efforts that the individual produces and then develops against potential environmental demands when faced with any stressor. It has been suggested that using the internet as a tool to cope with stressful life events contributes to general internet addiction (12). Those with internet addiction were shown to have a tendency towards a more impulsive coping strategy (13). In addition, it was stated that excessive internet use is another way of dealing with a number of difficulties faced in daily life (14). A study conducted in our country reported that those having low smartphone addiction scores obtained significantly higher scores in the "planned problem solving coping strategy" than those with high scores (15). In other words, it can be said that those with higher levels of smartphone addiction use have more dysfunctional coping strategies. Another study on coping skills focused on problematic internet use (PIU), a concept associated with smartphone addiction. PIU was defined by Davis (16) and Caplan (17) as an individual's inability to control internet usage, excessive use of it, and therefore having serious problems in interpersonal relationships and professional life. A study reported that those with high coping skills and who do not use the internet in expectation of increasing positive mood or reducing negative mood, are less likely to have a problematic internet use (18).

Like coping with stress, problem-solving skill has an important place in an individual's life and is accepted as an indicator for psychological resilience (19). Problemsolving skill is a cognitive and behavioral process that includes identifiying effective alternatives to cope with the problematic situation, choosing one of them, and implementing this selected situation (20). When faced with a particular problem, the ability to analyze and make decisions is extremely important, and in fact, individuals use their own personalities, upbringing styles and academically acquired skills, as well as individual problem-solving and decision-making skills without realizing it in this process (21). As a matter of fact, many studies have shown that using an ineffective problem-solving approach in the face of stressful events increases the probability of experiencing psychological problems $(22,23)$. In a study conducted with high school students in relation to smartphone addiction, a positive significant relationship was found between students' internet addiction levels and problem solving skill scores (24). Although there have been numerous studies on smartphone addiction, there has not been a study in Turkey that examines the impact of individuals' problem solving and stress-solving skills on smartphone addiction. Therefore, in this study, firstly, it is aimed to examine the effect of problem-solving skills and coping style on smartphone addiction. It is thought that the coping style and problem solving skills used by the individual in the face of a number of stressors during the day would predict smartphone addiction. Another objective of the study is to investigate the sociodemographic variables associated with the smartphone addiction in adult samples in Turkey.

\section{METHOD}

\section{Sampling}

The sample of this study consists of adults between the ages of 20 and 60, and internet-based data collection was used in the study. Considering the number of variables and the analyzes to be applied, the number of participants was decided to be 306 using the $G^{*}$ power program.

\section{Measures}

Demographic Information Form: Designed by the researchers this form includes quetions on gender, age, marital status, educational attainment, occupation, income level, as well as daily smartphone usage time. 
The Smartphone Addiction Scale: The Smartphone Addiction Scale was developed by Kwon et al. (5) and adapted into Turkish by Demirci et al. (25). The scale includes 33 items related to smartphone usage situations and the answer set is a 6-point Likert format ranging from "Absolutely yes" to "Absolutely not". The scale does not have a cut-off score, and higher scores from the scale indicate an increased risk of smartphone addiction. The Cronbach Alpha internal consistency coefficient was 0.95 and the Guttman Splithalf coefficient was found to be 0.89 in the split-half reliability analysis. Test-retest reliability was shown to be high ( $\mathrm{r}=0.814)(25)$.

The Problem Solving Inventory: Developed by Heppner and Peterson (26) to capture the awareness of individuals' problem-solving skills, this scale was adapted into Turkish by Sahin et al. (27). This scale that can be applied to adolescents and adults, classifies problemsolving skills under six sub-dimensions. These dimensions are the hasty approach (9 items), thoughtful approach (5 items), avoidant approach (4 items), evaluative approach (3 items), self-confident approach (6 items), and planned approach (4 items). In this scale, alternative behaviors on how the participants behave when faced with a problem are listed and the question "How often do you behave like this?" is posed. The set of responses in this scale consisting of 35 items and is a 6-point Likert type, ranges between "I always behave like this" and "I never behave like that." The Cronbach Alpha value for the internal consistency of the scale is found to be 0.88 , the test-retest reliability is reported in the range of 0.83 and 0.89 , and the split-half reliability is 0.81 (27).

Ways of Coping Inventory: Developed by Folkman and Lazarus (28) to determine which way individuals prefer to cope with stress, this scale was adapted into Turkish by Sahin and Durak (29). This scale detects which participants prefer optimistic (5 items), selfconfident (7 items), seeking of social support (4 items), helpless (8 items) and submissive (6 items) approaches when dealing with stress. At the same time, these coping ways form the sub-dimensions of the scale. Although the original version of the scale consists of 74 items, it was reduced to 30 items when translated into Turkish, and it is of 4-point Likert type. As a result of the reliability and validity studies of the short form, the internal consistency coefficient of the scale was found to be between 0.45 and 0.80 (29).

\section{Process}

Before starting data collection, approval was obtained from the Ankara Yıldırım Beyazıt University Ethics
Committee. After obtaining ethical approval with the research code 2018-230, data were collected between 29.07.2018 and 04.11.2018. The research data was collected through the snowball sampling method and the internet-based data collection method Google Form. The data was collected from each participant one at a time. The response time of the participants to all questions lasted between 15 and 20 minutes. A total of 318 participants agreed to participate in the study, but 12 of them were excluded later because they reported not using smartphones. As a result, the study was conducted with the data obtained from 306 participants. In the study, participants were asked to rate the Ways of Coping Inventory to detect their preference for problem-solving styles, the Problem Solving Inventory to detect their awareness for problem-solving skills, and the Smartphone Addiction Scale to assess their addiction to the smartphone which was the dependent variable of the study.

\section{Statistical Analysis}

Before the statistical analysis, a normality test was carried out to verify the assumption that the data was distributed normally. To examine the normal distribution results for the variables, the asymmetry (skewness) and tailedness (kurtosis) values of the variables were examined. The Skewness and Kurtosis values of the scales of smartphone addiction, coping styles and problem-solving approaches were respectively $0.20,-0.53 ;-0.11,1.19$; It is $0.36,-0.03$, and according to the normal distribution table put forward by George and Mallery (30), it was observed that these variables show normal distribution. The analysis of the data collected during the research was carried out in the SPSS 25.0 package program. In this study, the Pearson Product Moment Correlation Coefficient was used to see the relationship between basic variables. Independent $t$-test and analysis of variance (ANOVA) were carried out to examine whether there was any difference between smartphone addiction scores and sociodemographic variables. Hierarchical Regression Analysis was applied to determine sociodemographic variables and independent variables that affect smartphone addiction. In our study, $\mathrm{p}<0.05$ was taken as the significance level in all tests.

\section{RESULTS}

A total of 306 adults, 183 females (59.80\%) and 123 males (40.20\%) participated in the study and their average age was 28.37. Participants' daily smartphone usage time is 
between 2-3 hours. Information on the sociodemographic characteristics of the participants is given in Table 1 .

\section{Correlation Analysis}

Pearson Product Moment Correlation Coefficient analysis was conducted to examine the relationship between smartphone addiction, problem-solving skills, and the way of coping with stress. Considering the results of the correlation analysis; there was a significant positive relationship between the smartphone addiction and the hasty $(\mathrm{p}<0.05 ; \mathrm{r}=0.15)$, non-self-confident $(\mathrm{p}<0.05 ; \mathrm{r}=0.20)$ and submissive $(\mathrm{p}<0.05 ; \mathrm{r}=0.19)$ ways of problem-solving skills. The results of correlation analysis regarding the subscales of problem-solving skills and stress coping skills are shown in Table 2 . Descriptive statistics of the scales used in the study are given in Table 3.

\section{Analysis of Variables Associated with Smartphone Addiction}

Independent $t$-test and analysis of variance (ANOVA) were applied respectively to examine whether there was any differentiation between smartphone addiction scores and gender, age, and smartphone usage time. In these analyzes, smartphone addiction was considered as the dependent variable and other sociodemographic variables as independent variables.

The independent $t$ test analysis revealed that smartphone addiction differentiated significantly with regard to the gender variable $(\mathrm{t}=-2.32 ; \mathrm{p}<0.05)$. Accordingly, the smartphone addiction levels of men $(X=2.86 ; \mathrm{SD}=0.85)$ were found to be significantly higher than women $(\mathrm{X}=2.65 ; \mathrm{SD}=0.74)$.

In this study, participants were divided into the first (early) adulthood and middle adulthood in order to examine if the level of smartphone addiction significantly differentiate by age. According to the development model of Havighurst (31), the first adulthood period of an individual is between the ages of 18-30 and it ends with a mid-life crisis whereas the middle adulthood is defined as the time between 30 and 60 years old. Based on the independent $t$ test analysis conducted with regard to this model, the level of smartphone addiction differs significantly by age $(\mathrm{t}=$ 4.70; $\mathrm{p}<0.001)$. It is seen that those who are in the first (early) adulthood $(\mathrm{X}=2.88 ; \mathrm{SD}=0.81$ ) have a higher level of smartphone addiction than those in the middle adulthood $(\mathrm{X}=2.44 ; \mathrm{SD}=0.66)$. The final analysis of variance revealed that the smartphone addiction level varies significantly $(\mathrm{F}=11.52 ; \mathrm{p}<0.001)$ by the smartphone usage time. According to the post-hoc
Table 1: Participants' sociodemographic and defining characteristics

\begin{tabular}{lcc}
\hline $\begin{array}{l}\text { Gender } \\
\text { Woman }\end{array}$ & $\mathbf{n}$ & $\%$ \\
$\quad$ Man & 183 & 59.8 \\
Age & 123 & 40.2 \\
20-30 years & & \\
31-60 years & 206 & 67.32 \\
\end{tabular}

\section{Educational attainment}

\begin{tabular}{|c|c|c|}
\hline Literate-primary school graduate & 27 & 8.8 \\
\hline Secondary school-high school graduate & 161 & 52.6 \\
\hline Bachelor and above & 118 & 38.6 \\
\hline \multicolumn{3}{|l|}{ ccupation } \\
\hline Student & 133 & 43.5 \\
\hline Unemployed & 16 & 5.2 \\
\hline Housewife & 38 & 12.4 \\
\hline Trader/self-employed & 36 & 11.8 \\
\hline Goverment official & 22 & 7.2 \\
\hline Mmebers of lerned profession & 61 & 19.9 \\
\hline \multicolumn{3}{|l|}{ come } \\
\hline Non earning & 122 & 39.9 \\
\hline $1400 \mathrm{TL}$ and below & 62 & 20.3 \\
\hline $1400 \mathrm{TL}-2800 \mathrm{TL}$ & 59 & 19.3 \\
\hline 2801 TL-4200 TL & 34 & 11.1 \\
\hline $4201 \mathrm{TL}-5600 \mathrm{TL}$ & 26 & 8.5 \\
\hline $5601 \mathrm{TL}$ and/or over & 3 & 1.1 \\
\hline \multicolumn{3}{|l|}{ larital status } \\
\hline Single & 199 & 65.0 \\
\hline Married & 101 & 33.0 \\
\hline Widow/divorced & 6 & 2.0 \\
\hline \multicolumn{3}{|l|}{ sychological disorder } \\
\hline Yes & 36 & 11.8 \\
\hline No & 270 & 88.2 \\
\hline \multicolumn{3}{|l|}{ dverse life experince } \\
\hline Yes & 35 & 11.4 \\
\hline No & 271 & 88.6 \\
\hline \multicolumn{3}{|l|}{ aily smartphone usage time } \\
\hline Less than 30 min & 7 & 2.3 \\
\hline Between 30 min-1 hour & 29 & 9.5 \\
\hline Between 1 hour- 2 hours & 47 & 15.4 \\
\hline Between 2 hours- 3 hours & 76 & 24.8 \\
\hline Between 3 hours- 4 hours & 51 & 16.7 \\
\hline 4 hours and over & 96 & 31.4 \\
\hline
\end{tabular}

Tukey analysis, the smartphone addiction levels for those using a smartphone for 4 hours or more in a day $(\mathrm{X}=2.92 ; \mathrm{SD}=0.84)$ are more compared to those using it 
Table 2: Correlation coefficients between the scores obtained from the scale and subscales

\begin{tabular}{lcccccccccccc} 
& $\mathbf{1}$ & $\mathbf{2}$ & $\mathbf{3}$ & $\mathbf{4}$ & $\mathbf{5}$ & $\mathbf{6}$ & $\mathbf{7}$ & $\mathbf{8}$ & $\mathbf{9}$ & $\mathbf{1 0}$ & $\mathbf{1 1}$ & $\mathbf{1 2}$ \\
\hline $\mathbf{2}$ & $0.13^{*}$ & 1 & - & - & - & - & - & - & - & - & - & - \\
$\mathbf{3}$ & -0.02 & $0.15^{* *}$ & 1 & - & - & - & - & - & - & - & - & - \\
$\mathbf{4}$ & -0.10 & 0.07 & 0.10 & 1 & - & - & - & - & - & - & - & - \\
$\mathbf{5}$ & -0.07 & -0.06 & $0.13^{*}$ & 0.06 & 1 & - & - & - & - & - & - & - \\
$\mathbf{6}$ & $-0.16^{* *}$ & -0.09 & 0.09 & $0.13^{*}$ & $0.12^{*}$ & 1 & - & - & - & - & - & - \\
$\mathbf{7}$ & $-0.16^{* *}$ & -0.01 & $0.15^{*}$ & $0.28^{* *}$ & 0.03 & $0.14^{*}$ & 1 & - & - & - & - & - \\
$\mathbf{8}$ & $-0.14^{* *}$ & -0.08 & -0.01 & $0.22^{* *}$ & 0.08 & 0.08 & $0.19^{* *}$ & 1 & - & - & - & - \\
$\mathbf{9}$ & $0.22^{* *}$ & -0.06 & $-0.32^{* *}$ & $-0.21^{* *}$ & $-0.19^{* *}$ & -0.05 & $-0.31^{* *}$ & -0.06 & 1 & - & - & - \\
$\mathbf{1 0}$ & $0.30^{* *}$ & -0.00 & $-0.28^{* *}$ & $-0.23^{* *}$ & -0.09 & $-0.13^{*}$ & $-0.22^{* *}$ & $-0.15^{* *}$ & $0.65^{* *}$ & 1 & - & - \\
$\mathbf{1 1}$ & $-0.21^{*}$ & $0.20^{* *}$ & $0.24^{* *}$ & $0.12^{*}$ & 0.01 & -0.05 & 0.09 & $0.14^{*}$ & $-0.34^{* *}$ & $-0.42^{* *}$ & 1 & - \\
$\mathbf{1 2}$ & 0.07 & $0.19^{* *}$ & $0.20^{* *}$ & 0.10 & -0.01 & $-0.15^{* *}$ & -0.01 & -0.03 & $-0.15^{*}$ & 0.02 & $0.43^{* *}$ & 1 \\
$\mathbf{1 3}$ & 0.07 & -0.10 & $-0.13^{*}$ & -0.02 & -0.04 & 0.08 & -0.06 & 0.02 & $0.23^{* *}$ & $0.19^{* *}$ & -0.09 & $-0.14^{*}$ \\
\hline
\end{tabular}

1: Gender, 2: Smartphone addiction, 3: Hasty approach in problem-solving 4: Thougtful approach in problem-solving 5: Avoidant approach in problem-solving, 6: Evaluative approach in problem-solving, 7: Self-confident approach in problem solving, 8: Planned approach in problem-solving, 9: Self-confident approach in coping with stress, 10: Optimistic approach in coping with stress, 11: Helpless approach in coping with stress, 12: Submissive approach in coping with stress,

13: Seeking of social support approach in coping with stress, ${ }^{*} p<0.05,{ }^{* *} p<0.01$

Table 3: Average and standard deviation values of scale total scores

\begin{tabular}{lccccc} 
& Mean & SD & Minimum & Maximum & Cronbach Alpha \\
\hline The Smartphone Addiction Scale & 90.24 & 0.80 & 33 & 156 & 0.94 \\
The Problem Solving Inventory & 142.36 & 22.23 & 72 & 195 & 0.87 \\
The Ways of Coping Inventory & 75.73 & 7.79 & 42 & 101 & 0.64 \\
\hline
\end{tabular}

SD: Standard deviation

between 30 minutes and 1 hour $(\mathrm{X}=2.29$; $\mathrm{SD}=0.66)$. Detailed statistical results of the independent Student's t-test and variance analysis are given in Table 4.

\section{Regression Analysis Results}

In this study, regression analysis was carried out to examine the effect of problem solving skills and coping with stress on smartphone addiction. In order to control the effect of demographic variables, gender and smartphone usage time were added in the first block. In the second block, "insecure and submissive approach", was included in the analysis from the subscales of the way they dealt with stress.

In the hierarchical regression analysis, the first stage statistics showed that the model was found to be significant $\left(F\right.$ change $=15.96 ; R=0.31 ; R^{2}=0.09 ; p<0.05$ ). In other words, gender and smartphone usage time variables explain $9 \%$ of the change in smartphone addiction. The variables included in the analysis, gender $(B=0.18 ; t=3.18 ; p<0.05)$ and daily smartphone usage time $(\beta=0.28 ; t=5.11 ; p<0.05)$, was found to be significantly predicted the smartphone addiction.

In the second phase of the hierarchical regression analysis, in addition to demographic variables, the "insecure and submissive way sub-dimensions" of the coping with stress scale, which were found to have a significant relationship with smartphone addiction in correlation analysis, were included. Statistical analysis revelaed that the model was significant $(\mathrm{F}$ change $=8.46$; $\left.\mathrm{R}=0.38 ; \mathrm{R}^{2}=0.14 ; \mathrm{p}<0.05\right)$ and variables accaounted for $14 \%$ of the total variance on smartphone addiction. In other words, the effect of gender $(\beta=0.20 ; t=3.56$; $p<0.05)$, smartphone usage time $(B=0.26 ; t=4.74$; $\mathrm{p}<0.05)$ and insecure way of coping with stress $(B=0.16 ; t=2.58 ; p<0.05)$ was found to be significant in predicting smartphone addiction. It was observed that the submissive way of the stress coping scale had no effect on smartphone addiction $(\beta=0.10 ; t=1.70$; $\mathrm{p}>0.05$ ).

As a result, it was revealed that gender, smartphone usage time and insecure way of coping with stress significantly predicted smartphone addiction. Considering the variables that were effective in making the model significant; it can be said that smartphone addiction levels of male participants are significantly higher than female participants, the more daily smartphone use time increases, the higher the level of smartphone addiction, and those being insecure in 
Table 4: Correlation between smartphone addiction and sociodemographic variables

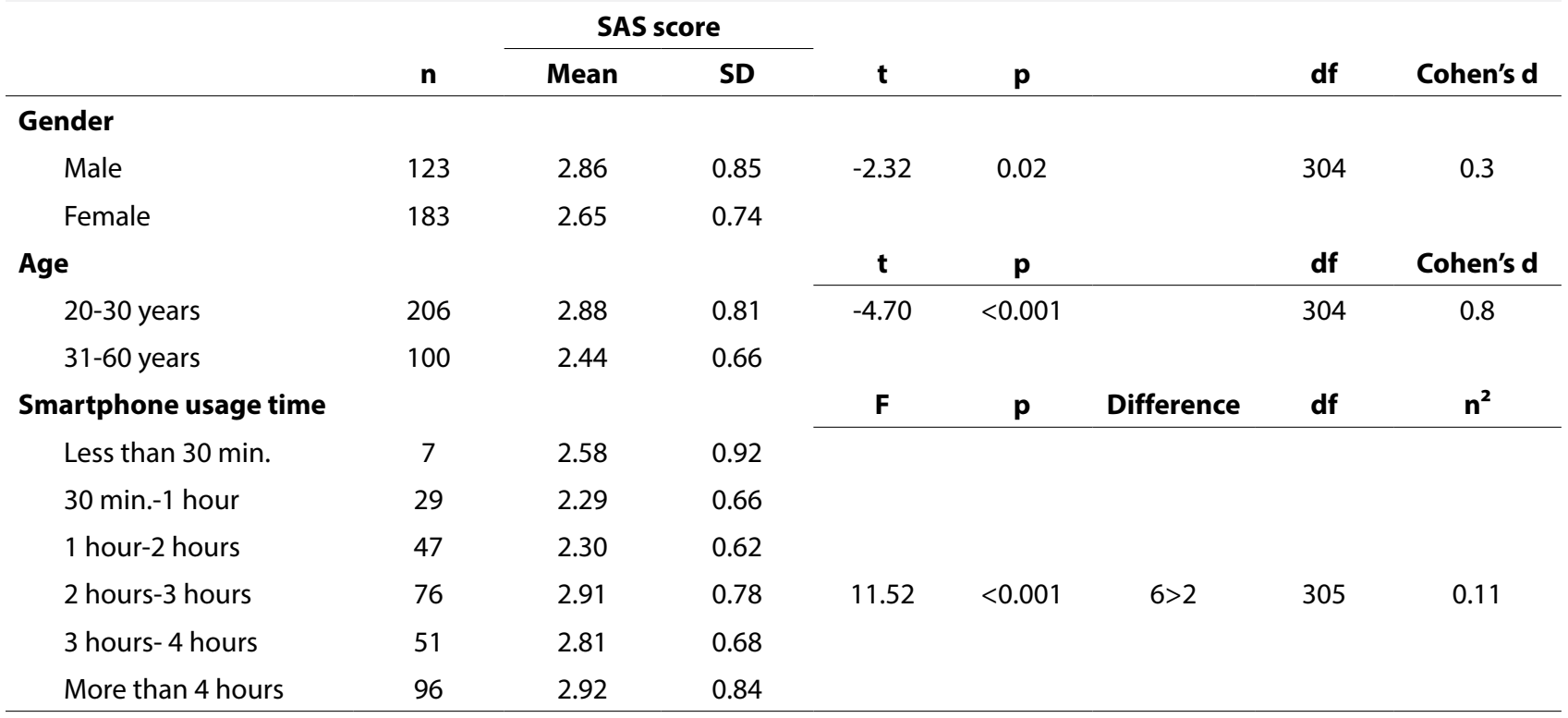

SD: Standard deviation, SAS: Smartphone Addiction Scale, $p<0.05$ is considered statistically significant

coping with stress have higher levels of smartphone addiction than those choosing other coping ways. Regression analysis results are given in Table 5.

\section{DISCUSSION}

In this study, the relationships between smartphone addiction and some sociodemographic variables were examined first. Firstly, smartphone addiction scores were evaluated in terms of gender, and it was found that men had significantly higher smartphone addiction scores than women. Consistent with this finding from our study, many studies on addiction revealed that men use the internet more and in relation to this they have a higher risk of internet addiction (32-34). In addition, internet addiction is reported to be much more common in men (especially male adolescents) regardless of the individual's culture (35). This is explained by the fact that men are more interested in technology than women (36) and are more open to technological innovations (37). However, according to some studies, this result regarding gender is controversial. To them, with the increase in internet usage, women, as well as men, maybe over-involved with their smartphones and there may be no difference in terms of internet and smartphone addiction in terms of gender $(38,39)$.

Analysis in our study revealed that smartphone addiction varies significantly concerning the age variable. According to the lifelong development approach, adulthood is divided into three periods as "first, middle and advanced adulthood" $(40,41)$. Between the ages of $18-30$ is considered as the first (early) adulthood, and between the ages of 30-60, as middle adulthood. Because following the purpose of the study data was collected only from the adults between

Table 5: Predictors of smartphone addiction according to hierarchical regression analysis

\begin{tabular}{|c|c|c|c|c|c|}
\hline & B & Standard error & Beta & $\mathbf{t}$ & $\mathbf{p}$ \\
\hline \multicolumn{6}{|l|}{$1^{\text {st }}$ stage } \\
\hline Gender & 0.28 & 0.09 & 0.18 & 3.18 & 0.002 \\
\hline Smartphone usage time & 0.16 & 0.03 & 0.28 & 5.11 & $<0.001$ \\
\hline \multicolumn{6}{|l|}{$2^{\text {nd }}$ stage } \\
\hline Gender & 0.32 & 0.09 & 0.20 & 3.56 & $<0.001$ \\
\hline Smartphone usage time & 0.14 & 0.03 & 0.26 & 4.74 & $<0.001$ \\
\hline Helpless approach in coping with stress & 0.23 & 0.09 & 0.16 & 2.58 & 0.01 \\
\hline Submissive approach in coping with stress & 0.17 & 0.10 & 0.10 & 1.70 & 0.09 \\
\hline
\end{tabular}

$\mathrm{p}<0.05$ is considered statistically significant. In the first stage, gender and smartphone usage time, in the second stage, the Self-Confident Approach and the Submissive Approach sub-dimensions of the Ways of Coping Inventory were included in the regression model 
the ages of 20-60, advanced adults were not included. The findings obtained from the study revealed that individuals in their middle adulthood have fewer smartphone addiction scores than those in their first (early) adulthood. It is noticed that there are many studies consistent with this result (42-44). According to these studies, it can be said that the life experiences of individuals between the ages of 30 and 60 have less risk for behavioral addiction due to increased emotional and self-regulation skills. Individuals in their middle adulthood are less interested in technology and technological products compared to young people (42), and adolescents or individuals in their early adulthood have more likely smartphone addiction compared to the elderly (43). Besides, according to another study, as individuals get older, they use smartphones less and become more skilled in self-regulation, and start using the phone less for socialization (44). In conclusion, when looking at which age groups are most prone to smartphone addiction, it can be said that young individuals are more prone to overuse of new technologies and have a higher risk of developing smartphone addiction (45-48).

In this study, the relationship between daily smartphone usage time and smartphone addiction scores was examined and it was concluded that as the duration of usage increased, the level of addiction also increased. This finding is consistent with the other studies that found that smartphone addiction level is positively correlated with the increase in daily smartphone usage time $(43,49)$. In addition, a study showed that smartphone-addicted users used their smartphones twice as much during the day compared to non-addicts (50).

The main objective of the present study is to investigate the impact of problem-solving skills and stress coping ways on smartphone addiction level. Accordingly, it has been revealed that having an insecure way of coping with stress renders smartphone addiction significant in a positively related manner. In other words, smartphone addiction scores of participants who display an insecure way are significantly higher than other ways used in coping with stress. Considering that there are fewer studies on smartphone addiction compared to internet addiction and problematic internet use in the literature, the findings related to problemsolving and coping with stress are mostly discussed over these two variables. Accordingly, there are numerous studies showing the negative relationship between selfconfidence and self-esteem $(51,52)$. In other words, the self-esteem of individuals who are not self-confident is low and their attitude towards the problems they face is also affected by this situation. In a study, it was shown that smartphone addiction is negatively associated with self-esteem and positively associated with the level of stress experienced $(53,54)$. Accordingly, low self-esteem is positively associated with the over-use of smartphones (55) and smartphone addiction (56). In another study, it was shown that individuals with low self-esteem use the internet to compensate for the problems they experience in thier social relationships (57), and in addition, low self-esteem is also reported to be a risk factor for problematic internet addiction (58-60). Lack of selfconfidence can cause individuals to avoid face-to-face relationships and spend most of their time in front of the screen and express themselves in a virtual environment such as the internet. Therefore, considering the positive relationship between internet addiction (6163) and self-insecurity (64), it is indicated that low level of self-confidence will strengthen this relationship considerably. Insecure individuals need approval from others, as well as a sense of belonging, which leads them to have a greater risk of behavioral addiction (54). In addition, the correlation analysis showed that there was a poor correlation between the smartphone addiction scale and the sub-dimensions of the problem-solving skills scale, so this variable was not included in the regression analysis. However, considering some studies in the literature, not using problem-oriented coping skills is an important risk factor for smartphone addiction (65). In another study, it was revealed that those with problematic internet use had more avoidant way of coping than those in the control group (66). In addition, it has been found that using maladaptive coping, such as avoidance, rather than having an adaptative coping style such as planned problem solving and seeking social support, has a significant impact on problematic internet use (67). In this study, the characteristics of the sample may have been effective because this variable was not included in the model.

The study has some limitations. Although internetbased data collection has advantages such as not allowing participants to leave items blank and ensuring data to be easily collected in a shorter time, this can be seen as a limitation. In addition, although it was considered that the participants would fill the scales in this study from their own smartphones and measures were taken by giving the information that anonymity would be achieved in particular, in general self-report scales can increase the tendency to respond according to social willingness. The evaluation of smartphone addiction with only the self-report tool, the fact that this 
type of addiction is still a topic of discussion, and the lack of a cut-off score of the smartphone addiction scale used in the study can be considered as a limitation.

In summary in this study, it was found that men, those who were in their first (early) adulthood, and those with a high smartphone usage time and those with an insecure coping style, were more at risk for smartphone addiction. It can be said that having an insecure coping way when trying to cope with the events faced by individuals poses a risk to smartphone addiction and increases the possibility of smartphone addiction which is a behavioral addiction. Since our study is the first study, as far as we know, investigating the impact of problem-solving skills and stress-dealing styles on smartphone addiction, important results were obtained. It provided important information that specialists working in the field of behavioral addiction should also focus on coping with stress and the copingway of it while planning the treatment process. In addition, considering that $25.63 \%$ of the general population in our country consists of young adults (68), it is thought that it will be useful to increase the number of studies on this subject and to use the results from this study for the protection and prevention programs related to smartphone addiction.

\begin{tabular}{|c|c|c|}
\hline \multicolumn{2}{|c|}{ Contribution Categories } & \multirow{2}{*}{\begin{tabular}{|l} 
Author Initials \\
R.A., H.S.G.
\end{tabular}} \\
\hline \multirow{3}{*}{ Category 1} & Concept/Design & \\
\hline & Data acquisition & R.A. \\
\hline & Data analysis/Interpretation & R.A., H.S.G. \\
\hline \multirow{2}{*}{ Category 2} & Drafting manuscript & R.A., H.S.G. \\
\hline & Critical revision of manuscript & H.S.G. \\
\hline Category 3 & Final approval and accountability & R.A., H.S.G \\
\hline \multirow{2}{*}{ Other } & Technical or material support & N/A \\
\hline & Supervision & N/A \\
\hline
\end{tabular}

Ethics Committee Approval: This study approval was obtained by the Ankara Yildirim Beyazit University Ethics Committee (Number: 2018-230).

Informed Consent: Written informed consent obtained.

Peer-review: Externally peer-reviewed.

Conflict of Interest: The authors declared no conflict of interest.

Financial Disclosure: The authors declared no financial disclosure.

\section{REFERENCES}

1. Yurdagul B. What is a smartphone, what is its use? Worldwide rates of smartphone use and the situation in Turkey. Android Turkiye, 2011. URL: https://androidtrdotnet.wordpress.com/2011/12/24/ akilli-telefon-nedir-ne-ise-yarar-dunyadaki-akilli-telefonkullanim-oranlari-ve-turkiyedeki-durum/. Accessed: July 17, 2020. (Turkish)
2. Ugur N, Turan A. College students' acceptance and usage of mobile applications: Sakarya University case. Journal of Internet Applications and Management 2015; 6:63-79. (Turkish)

3. Griffiths MD. Technological addictions. Clinical Psychology Forum 1995; 76:14-19.

4. Lin YH, Chang LR, Lee YH, Tseng HW, Kuo TB, Chen SH. Development and validation of the Smartphone Addiction Inventory (SPAI). PLoS One 2014; 9:e98312.

5. Kwon M, Lee JY, Won WY, Park JW, Min JA, Hahn C, et al. Development and validation of a smartphone addiction scale (SAS). PLoS One 2013; 8:e56936.

6. Say G, Durak Batigun A. The Assessment of the relationship between problematic internet use and parent-adolescent relationship quality, loneliness, anger, and problem solving skills. Dusunen Adam The Journal of Psychiatry and Neurological Sciences 2016; 29:324-334.

7. Ozen S, Topcu M. The relationship of smartphone addiction with depression, obsession-compulsion, impulsivity, alexithymia among medical faculty students. Journal of Dependence 2017; 18:16-24. (Turkish)

8. Zywica J, Danowski J. The faces of facebookers: Investigating social enhancement and social compensation hypotheses; predicting FacebookTM and offline popularity from sociability and self-esteem, and mapping the meanings of popularity with semantic networks. J Comput Mediat Commun 2008; 14:1-34.

9. Elhai JD, Tiamiyu MF, Weeks JW, Levine JC, Picard KJ, Hall BJ. Depression and emotion regulation predict objective smartphone use measured over one week. Pers Individ Dif 2018; 133:21-28.

10. Kim E, Cho I, Kim EJ. Structural Equation Model of Smartphone Addiction Based on Adult Attachment Theory: Mediating Effects of Loneliness and Depression. Asian Nurs Res (Korean Soc Nurs Sci) 2017; 11:92-97

11. Folkman S, Lazarus RS. Manual for the Ways of Coping Scale. Palo Alto CA: Consulting Psychology Press, 1988.

12. Tang J, Yu Y, Du Y, Ma Y, Zhang D, Wang J. Prevalence of internet addiction and its association with stressful life events and psychological symptoms among adolescent internet users. Addict Behav 2014; 39:744-747.

13. Tonioni F, Mazza M, Autullo G, Cappelluti R, Catalano V, Marano G, Fiumana V, Moschetti C, Alimonti F, Luciani M, Lai C. Is Internet addiction a psychopathological condition distinct from pathological gambling? Addict Behav 2014; 39:1052-1056.

14. Kardefelt-Winther D. A conceptual and methodological critique of internet addiction research:towards a model of compensatory internet use. Comput Hum Behav 2014; 31:351-354.

15. Toda M, Ezoe S, Takeshita T. Mobile phone use and stress-coping strategies of medical students. Int J Cyber Behav Psychol Learn 2014; 4:41-46.

16. Davis RA. A cognitive-behavioral model of pathological Internet use. Comput Hum Behav 2001; 17:187-195.

17. Caplan SE. Theory and measurement of generalized problematic Internet use: A two-step approach. Comput Hum Behav 2010; 26:1089-1097. 
18. Brand $M$, Laier $C$, Young KS. Internet addiction: coping styles, expectancies, and treatment implications. Front Psychol 2014;5:1256

19. Heppner PP, Krauskopf CJ. An information processing approach to personal problem solving. Couns Psychol 1987; 15:371-447.

20. Kneeland S. Problem Solving. Kalayci N (Translation Editor), Ankara: Gazi Kitabevi, 2001. (Turkish)

21. Arnold JD. The Complete Problem solver: A total system for competitive decision making. Canada: John Wiley \& Sons Inc, 1992.

22. D'Zurilla TJ, Nezu AM. Problem-solving therapies: In Dobson KS (editor). Handbook of Cognitive-Behavioral Therapies. New York, NY, US: Guilford Press, 2001, 211-245.

23. Nezu AM, Perri MG. Social problem-solving therapy for unipolar depression: an initial dismantling investigation. J Consult Clin Psychol 1989; 57:408-413.

24. Yuksel M, Yilmaz E. The Investigation of the relationship between Internet addiction and problem solving skills of high school students in terms of several variables. Elementary Education Online 2016; 15:1031-1042.

25. Demirci K, Orhan HA, Akpinar A, Sert H. Validity and reliability of the Turkish version of the Smartphone Addiction Scale in younger population. Bulletin of Clinical Psychopharmacology 2014; 24:226-234.

26. Hepper PP, Petersen CH. The development and implications of a personal problem-solving inventory. J Couns Psychol 1982; 29:66-75

27. Sahin NH, Sahin N, Hepper PP. Psychometric properties of the Problem Solving Inventory in a group of Turkish university students. Cognit Ther Res 1993; 17:379-376.

28. Folkman S, Lazarus RS. Stress, appraisal, and coping. New York: Springer Publishing Company, 1984, 150-153.

29. Sahin NH, Durak A. Stress Coping Style Inventory: adaptation for university students. Turk Psikoloji Dergisi 1995; 10:58-73.

30. George D, Mallery M. SPSS for windows step by step: a simple guide and reference, 17.0 Update. Tenth ed. Boston: Pearson, 2010 .

31. Havighurst RJ. Developmental tasks and education. Third ed. New York: David McKay Company, 1972.

32. Choo H, Sim T, Liau AKF, Gentile DA, Khoo A. Parental influences on pathological symptoms of video-gaming among children and adolescents: A prospective study. J Child Fam Stud 2015 ; 24:1429-1441.

33. Dhir A, Chen S, Nieminen M. Predicting adolescent internet addiction: The roles of demographics, technology accessibility, unwillingness to communicate and sought internet gratifications. Comput Hum Behav 2015; 51:24-33.

34. Wang L, Luo J, Bai Y, Kong J, Luo T, Gao W, Sun X. Internet addiction of adolescents in China: Prevalence, predictors, and association with well-being. Addict Res Theory 2013; 21:62-69.

35. Tsitsika A, Janikian M, Schoenmakers TM, Tzavela EC, Olafsson $\mathrm{K}$, Wójcik $\mathrm{S}$, et al. Internet addictive behavior in adolescence: a cross-sectional study in seven European countries. Cyberpsychol Behav Soc Netw 2014;17:528-535.

36. Servidio R. Exploring the effects of demographic factors, internet usage and personality traits on internet addiction in asample of Italian university students. Comput Human Behav 2014; 35:8592.

37. Ray CM, Sormunen C, Harris TM. Men's and women's attitudes toward computer technology: A comparison. ITLPJ 1999; 17:1-

38. Chiu SI, Hong FY, Chiu SL. An Analysis on the Correlation and Gender Difference between College Students' Internet Addiction and Mobile Phone Addiction in Taiwan. ISRN Addict. 2013; 2013:360607.

39. Walsh SP, White KM, Cox S, Young RM. Keeping in instant touch: The predictors of young Australians instant touch. Comput Hum Behav 2011; 27:333-342.

40. Levinson DJ. A conception of adult development. Am Psychol 1986; 41:3-13

41. Levinson DJ. The seasons of a woman's life. New York: Knopf, 1996.

42. Charness N, Bosman EA. Human factors and age: In Craik FIM, Salthouse TA (editors). The Handbook of Aging and Cognition. Hillsdale, NJ: Erlbaum, 1992, 495-551.

43. Lenhart A, Purcell K, Smith A, Zickuhr K. Social media \& mobile internet use among teens and young adults. Millennials 2010; 1-37.

44. Van Deursen AJ, Bolle CL, Hegner SM, Kommers PAM. Modeling habitual and addictive smartphone behavior: The role of smartphone usage types, emotional intelligence, social stress, self-regulation, age, and gender. Comput Hum Behav 2015; $45: 411-420$

45. Echeburúa E, de Corral P. Addiction to new technologies and to online social networking in young people: A new challenge. Adicciones 2010; 22:91-95. [Article in Spanish]

46. Haug S, Castro RP, Kwon M, Filler A, Kowatsch T, Schaub MP. Smartphone use and smartphone addiction among young people in Switzerland. J Behav Addict 2015; 4:299-307.

47. won M, Kim DJ, Cho H, Yang S. The smartphone addiction scale: development and validation of a short version for adolescents. PLoS One 2013; 8:e83558.

48. De-Sola Gutiérrez J, Rodríguez de Fonseca F, Rubio G. CellPhone Addiction: A Review. Front Psychiatry 2016; 7:175.

49. Dikec G, Kebapci A. Smartphone addiction level among a group of university students. Journal of Dependence 2018; 19:1-9. (Turkish)

50. Bagci H, Peşken MF. Investigating the smart phone addictions of vocational school students from different variables. Malaysian Online Journal of Educational Technology 2018; 6:40-52.

51. Coudevylle GR, Gernigon C, Ginis KAM. Self-esteem, selfconfidence, anxiety and claimed self-handicapping: A mediational analysis. Psychol Sport Exerc 2011; 12:670-675.

52. Campbell JD. Self-esteem and mn pşclarity of the self-concept. J Pers Soc Psychol 1990; 59:538-549. 
53. Lee HS. Convergent study of the effect of university students' addiction to smartphones on self-esteem and self-efficacy: stress level and mental health as mediating factors. Journal of the Korea Convergence Society 2017; 8:139-148.

54. Chen CY. Smartphone addiction: psychological and social factors predict the use and abuse of a social mobile application, Inf Commun Soc 2020; 23:454-467.

55. Beranuy M, Oberst U, Carbonell X, Charmarro A. Problematic internet and mobile phone use and clinical symptoms in college students: The role of emotional intelligence. Comput Hum Behav 2019; 25:1182-1187.

56. Ha JH, Chin B, Park DH, Ryu SH, Yu J. Characteristics of excessive cellular phone use in Korean adolescents. Cyberpsychol Behav 2008; 11:783-784.

57. Hong FY, Chiu SI, Huang DH. A model of the relationship between psychological characteristics, smartphone addiction and use of mobile phones by Taiwanese female university students. Comput Hum Behav 2012; 28:2152-2159.

58. Douglas AC, Mills JE, Niang M, Stepchenkova S, Byun S, Ruffini $\mathrm{C}$, et al. Internet addiction: Meta-synthesis of qualitative research for the decade 1996-2006. Comp Hum Behav 2008; 24:3027-44.

59. Yang SC, Tung CJ. Comparison of Internet addicts and nonaddicts in Taiwanese high school. Comp Hum Behav 2007; 23:7996.

60. Kim HK, Davis KE. Toward a comprehensive theory of problematic Internet use: Evaluating the role of self-esteem, anxiety, flow, and the self-rated importance of Internet activities. Comp Hum Behav 2009; 25;490-500.
61. Huan VS, Ang RP, Chye S. Loneliness and shyness in adolescent problematic internet users: the role of social anxiety. Child \& Youth Care Forum 2014; 43:539-545.

62. Moody EJ. Internet use and its relationship to lonelines. Cyberpsychol Behav 2001; 4:393-401.

63. Ang RP, Chong WH, Chye S, Huan VS. Loneliness and generalized problematic Internet use: Parents' perceived knowledge of adolescents' on-line activities as a moderator. Comp Hum Behav 2012; 28:1342-1347.

64. Iskender M. Investigation of the Effects of Social Self-Confidence, Social Loneliness and Family Emotional Loneliness Variables on Internet Addiction. Malaysian Online Journal of Educational Technology 2018; 6:1-10.

65. Seong MH, Nam HR. Influence of stress coping style, relationship ability and self-esteem on smartphone addiction in nuring student. Journal of the Korea Academia-Industrial Cooperation Society $2017 ; 18: 61-70$.

66. Li H, Wang J, Wang L. A survey on the generalized problematic Internet use in Chinese college students and its relations to stressful life events and coping style. Int J Ment Health Addict 2009; 7:333-346.

67. Endler NS, Parker JDA. Assessment of multidimensional coping: task, emotion, and avoidance strategies. Psychol Assess 1994; 6:50-60

68. Turkish Statistical Institute (TUIK). Household Information Technologies Use Survey. URL: http://tuik.gov.tr/ PreHaberBultenleri.do?id=21779. Accessed January 2019. (Turkish) 